\title{
Headwater-to-consumer Drinking Water Security Assessment Framework and Associated Indicators for Small Communities in High-income Countries
}

\author{
B. Deb Nath ${ }^{1}$ (D) C. J. Schuster-Wallace ${ }^{2}$ (D) S. E. Dickson-Anderson ${ }^{3}$ (ID
}

Received: 11 June 2021 / Accepted: 22 September 2021 / Published online: 7 February 2022

(c) The Author(s), under exclusive licence to Springer Nature B.V. 2022

\begin{abstract}
Drinking water insecurity in small and rural, remote, or otherwise marginalized communities in Canada is pervasive and complex with multiple dimensions and impacts. These communities face challenges such as variable source water quality, lack of resources, inappropriate treatment technologies, lack of access to training, difficulties retaining qualified personnel, and ineffective governance structures. Currently, there is a gap in the academic literature with respect to drinking water security assessment frameworks or tools for small and rural, remote, or otherwise marginalized communities, particularly in high income countries. Thus, the objective of this study is to introduce a framework for assessing drinking water security, from headwater to consumer, in the context of small and rural, remote, or otherwise marginalized communities.

An indicator-based framework has been developed to evaluate drinking water security, prioritize actions and investments, and support decision-making. The framework builds on expert knowledge and a critical review of security, sustainability, and performance indices of water supply and treatment processes obtained from the literature. The framework is organised into four dimensions of drinking water security from headwaters to consumer: upstream watershed security; source water security; community needs and engagement; and treatment and distribution infrastructure. A list of relevant indicators for each dimension has been compiled to support framework application in a format that is accessible to decision-makers in small and rural, remote, or otherwise marginalized communities.
\end{abstract}

Keywords Local water security $\cdot$ Drinking water security framework $\cdot$ Small systems $\cdot$ Rural remote or otherwise marginalized (RRM) communities · Assessment indicators and indices

Highlights

- Few rural drinking water security assessment tools exist for high-income countries

- Proposed framework recognizes system from headwater to consumer not just treatment and distribution

- Comprehensive set of indicators developed to account for specific rural water security challenges

- Critical non-traditional elements are community needs and engagement and environmental footprint

- Flexible weighting allows for broad application or comparisons

B. Deb Nath

debnathb@mcmaster.ca

Extended author information available on the last page of the article 


\section{Introduction}

\subsection{Significance}

Potable drinking water is universally recognized as a critical component of public health. In 2020, approximately $25 \%$ of the global population lacked safely managed drinking water services, with $80 \%$ of these living in rural areas (WHO and UNICEF 2021). In addition to the attention paid to access in low- and middle-income countries, provision of potable drinking water to small and rural, remote, or otherwise marginalized (RRM) communities in high-income countries has been the subject of increasing concern and investment over the last 30 years (McFarlane and Harris 2018). Small drinking water treatment systems in high-income countries, particularly those in RRM communities, face significant challenges (McFarlane and Harris 2018). For example, drinking water-related outbreaks affecting hundreds to thousands of people have occurred in high-income countries including Canada, (), the United States, and the United Kingdom (Hrudey and Hrudey 2007; Moreira and Bondelind 2017) in the last few decades. Despite significant progress in recent decades, small drinking water systems are still vulnerable to contamination and subject to frequent failure (Kot et al. 2015), and high risk systems still exist (Black and McBean 2017). As a result, drinking water advisories are frequently issued among small and RRM communities in Canada, especially in First Nation communities (Government of Canada 2021).

\subsection{Literature Review}

Assessment frameworks or guidelines can be effective tools in these contexts to fully understand the issues and develop appropriate solutions. A range of indicators have been proposed for different parts of the drinking water system as well as for water security more broadly across different community sizes and economic contexts (e.g., Dickson et al. 2016; Domínguez et al. 2019). In high-income contexts, drinking water indicators have typically been developed for urban or larger community contexts (e.g. Alegre et al. 2016; Van Engelenburg et al. 2019). However, needs and priorities are different in smaller communities due to their small customer base, geographic isolation, and limited available resources. Thus while rural communities are unlikely to fit into urban framings of drinking water security, very few studies have proposed water treatment performance indicators for small systems or rural settings. Existing indicators are site and scenario specific. For example, Coulibaly and Rodriguez (2004) identified performance indicators based on agricultural land use, raw water quality, treatment, infrastructure and maintenance, and finished water quality for drinking water utilities in Québec. Vieira et al. (2008) used slightly different indicators and added by-products management, safety, and human, economic, and financial resources. Molinos-Senante et al. (2019) moved away from physical treatment processes to identify quality indicators for service delivery and management, while Jones et al. (2019) took a broader view, considering affordability, global pollution, human health, and operational challenges. However, these are arguably not sufficiently comprehensive to reflect the ongoing complexity of challenges faced by these small and RRM communities. Large communities and urban centers typically have many resources available while the necessary tools to support understanding and assessment of local water security in small and RRM communities are scarce (Latchmore et al. 2018). Furthermore, values and uses 
of water differ between locations and cultures. For example, many Indigenous Peoples have spiritual connections to and rely on water for ceremonial purposes (Latchmore et al. 2018).

\subsection{Novelty and Contribution}

Unlike the more general definitions of water security that focus on safeguarding water for people and ecosystems now and in the future (e.g., WWAP 2015), drinking water security refers specifically to the uninterrupted provision of safely managed drinking water for all (Dunn et al. 2012). It moves beyond a traditional focus on the treatment and distribution infrastructure towards a recognition that drinking water security depends on the state and services of the broader system from headwater to consumer. This definition requires a new framing for drinking water system assessments as it sets baseline requirements for water resources management at the watershed scale and recognises the role of ecosystem services in drinking water provision. Using this novel framing and given diversity of RRM communities as well as a lack of indicators specific to RRM communities in high-income countries, the synthesis and development of a comprehensive and flexible set of drinking water security indicators is needed. The contribution of this study is a conceptual framework for drinking water security in high-income RRM community contexts together with a comprehensive and flexible set of metrics that can be used to develop a community-specific suite of indicators to assess drinking water security to inform drinking water security improvements.

\section{Conceptual Framework for Drinking Water Security}

The drinking water security system is conceptualised as consisting of the following elements (Fig. 1), situated within the broader context of budgets, legislation, and regulations: upstream watershed security; source water security; community needs and engagement; and treatment and distribution infrastructure.

Watershed Security Sustainable supply of drinking water depends largely on the upstream catchment or watershed, which is often neglected in drinking water studies yet is important for safe and sustainable water supplies. Watersheds provide several ecosystem services that

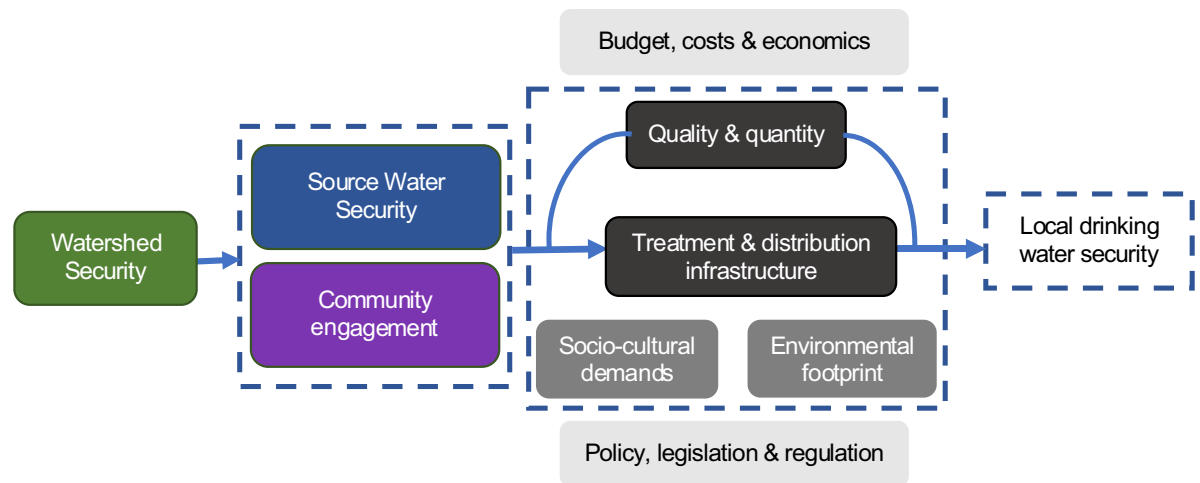

Fig. 1 A conceptual framing of the drinking water security system, with a focus on small and RRM communities 
ameliorate impacts from extreme and high impact weather-related events and improve water quality. This is more critical than ever given current and predicted impacts of climate change. Collectively, forests, natural vegetation, and wetlands stabilize and protect soils, increase infiltration, filter water, regulate pathogenic organisms, attenuate floods, sustain base flows, and generally buffer hydrologic extremes (Blumenfeld et al. 2009; Gartner et al. 2017). Together, these contribute to reduced drinking water treatment costs (Lopes et al. 2019).

Source Water Security Source water refers to the water bodies (including aquifers) used directly for drinking water production (Minnes and Vodden 2017). Type and performance of treatment infrastructure depends largely on the source (i.e., quantity, quality, and variability) (Edzwald 2011). It should be noted that climate change makes it difficult to anticipate future source water quantity and quality as it challenges the assumption of stationarity (Milly et al. 2008). This is of particular concern for small and RRM communities, which are less able to respond to significant source water variability.

Community Needs and Engagement There is no universal solution that will guarantee sustainability, but a better understanding of the socio-cultural context can help to develop more efficient and acceptable tools to make contextually appropriate decisions (Marshall 2015). Communities represent a critical element of drinking water security that are often neglected in current drinking water assessments. Plans for (economic) growth and other water uses that may not be typically considered (e.g., ceremonial) are essential for establishing current and future community needs. In many instances, focusing on what people actually need and want, rather than focusing on external determinations of their needs, leads to more appropriate, and therefore sustainable, designs (Marshall 2015). Many small communities have values or cultural beliefs that have implications for the type of treatment that is chosen. People have been known to use alternate sources that may not be as safe when treatment process or the finished water quality do not align with these values and beliefs (Latchmore et al. 2018). It is extremely difficult to identify these values, beliefs, resources, and needs without community participation, which also enhances engagement and stewardship (Forlee et al. 2014) as well as more sustainable solutions (Evans 2019), thereby reducing drinking water insecurity.

Governance, Regulation, and Oversight Due to their complex ownership and governance structures and frequent exemption from regulations and oversight, small systems may be subject to greater jurisdictional challenges than larger or publicly owned systems (Gunnarsdottir et al. 2015). These governance constraints may increase vulnerability to contamination events (Edwards et al. 2012), especially given that most drinking water regulation violations in small systems are a result of failing to meet monitoring and reporting requirements rather than water quality standards (Job 2011; Rubin 2013). Inadequate or overly prescriptive legislation and regulations can further restrict system efficiency and improvements, while fragmented, inconsistent, and partial regulation will perpetuate existing inequalities (Balazs et al. 2012). It is important to note that the scope of this theme, and therefore this framework, does not consider specific governance structures for water, which is an essential element of equitable water management, particularly for Indigenous Peoples (Irvine et al. 2020).

Treatment and Distribution Infrastructure The presence of water treatment and distribution infrastructure cannot guarantee drinking water security in rural and remote settings (Molinos-Senante et al. 2019). Sustainable infrastructure must: be appropriate for the social, 
economic, and regulatory contexts; meet performance criteria; fit within local fiscal, human, technical, and supply chain capacities; maximize energy efficiency; and, minimize the environmental footprint. Accordingly, the drinking water security system must be represented by a comprehensive watershed to consumer approach rather than just the treatment train and distribution system. Further, governments and decision-makers normally use technical and economic criteria to select and implement treatment facilities (e.g., Farmer et al., 2012; United States Environmental Protection Agency 2012). Yet, drinking water security encompasses social and ecological elements in addition to the technical elements of drinking water treatment that cannot always be distilled to the lowest dollar amount. These elements need to be prioritised differently in the decision process used to choose appropriate infrastructure solutions (Fig. 2). Of paramount importance is the protection of public health, which requires sufficient technical performance to deliver potable water. Socio-cultural appropriateness should help to ensure consumption of provisioned water, which is also critical to the protection of public health. Once these have been established, solutions must be narrowed to adhere to applicable legislation and regulations and then through consideration of local resources, environmental impacts, and sustainability. Costs should be the final consideration rather than the primary factor, inverting current approaches.

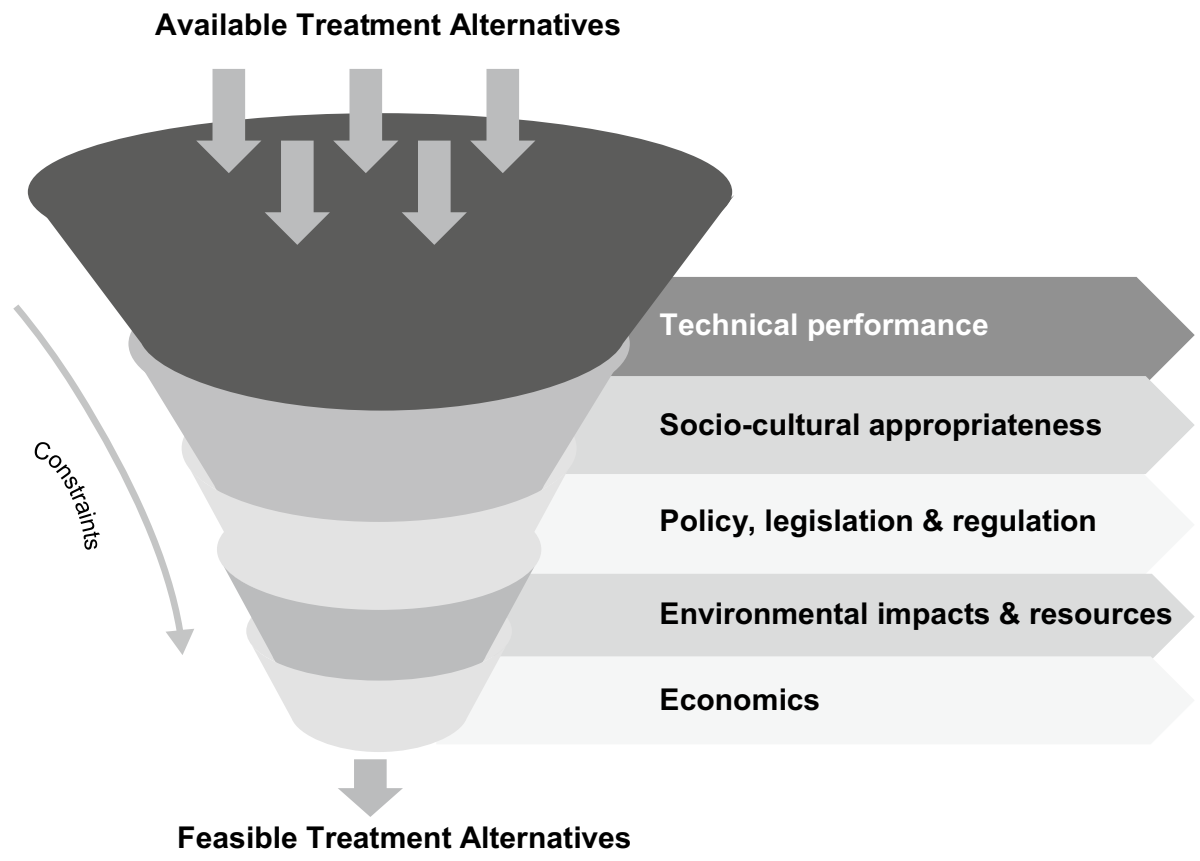

Fig. 2 A new prioritisation of elements in the decision-making process for the selection of a drinking water solution 


\section{Methodology}

Documented indicators, sustainability issues, and approaches used within or emerging from research networks, projects, and methods were identified and collated as a foundation for developing a concrete assessment framework for drinking water security and sustainability assessment. Relevant peer-reviewed journal and conference articles published in English between 2002 and 2020 were identified through a keyword search of all databases within Engineering Village (Supplementary Information S1, Table 1). Title and abstract were reviewed and articles included if they identified performance, sustainability, or security indicators for watershed, water sources, community engagement, water supply, treatment, or distribution infrastructure. Duplicates were removed and any additional references mined from full articles reviewed.

A total of 141 articles were initially identified with an additional 13 articles included from reference mining (see SI references). Relevant indicators to assess drinking water security and sustainability status were extracted into an Excel@ spreadsheet based on the thematic elements in the conceptual framework (Figs. 1 and S1). Indicators were chosen based on their simplicity and applicability for drinking water security assessment of small and RRM communities (Haider et al. 2014). Expert opinion and research experience of the authors were used to fill remaining gaps in the assessment framework.

\section{Results}

Based on previous studies, most indicators identified assess the technical, socio-cultural, environmental impacts, or economic sustainability of the system. Conversely, very few studies identified indicators for watershed security, source water security, or community engagement (Fig. 3). 


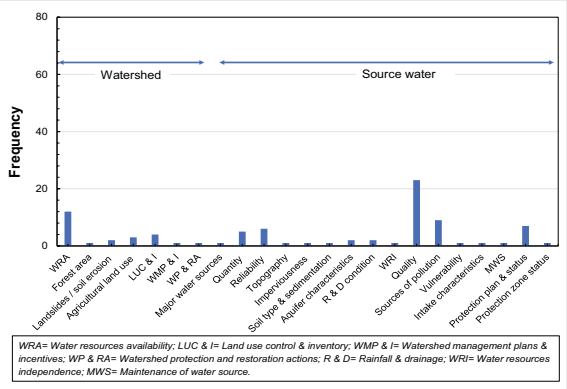

a) Watershed \& source water

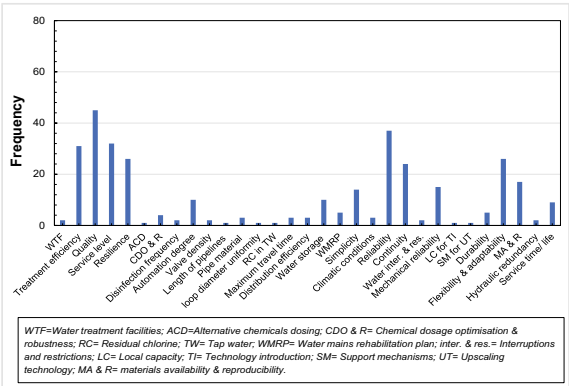

c) Technical performance (treatment $\&$ distribution)

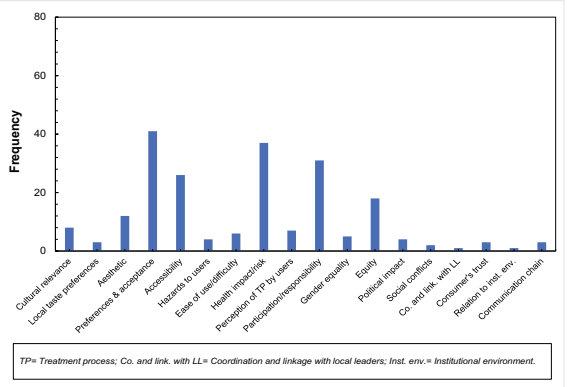

e) Socio-cultural aspects

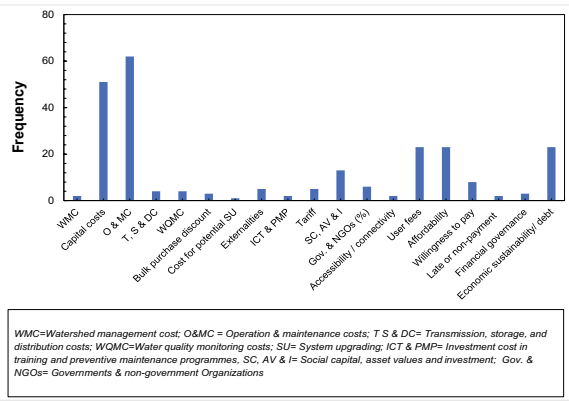

g) Budget, costs, \& equity

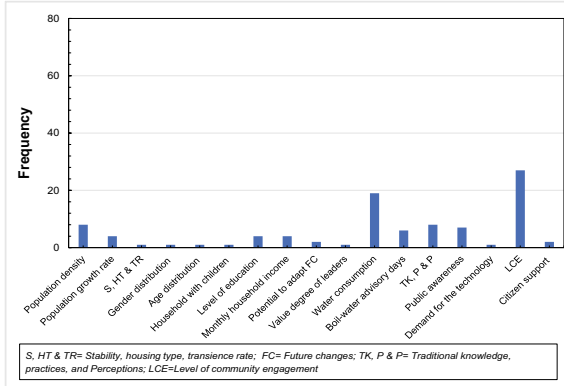

b) Community characteristics \& engagement

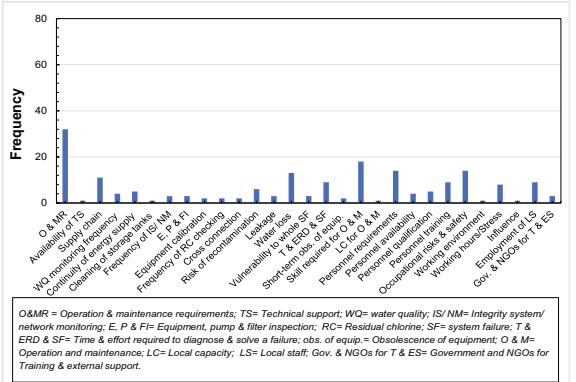

d) Technical performance (operation \& maintenance)

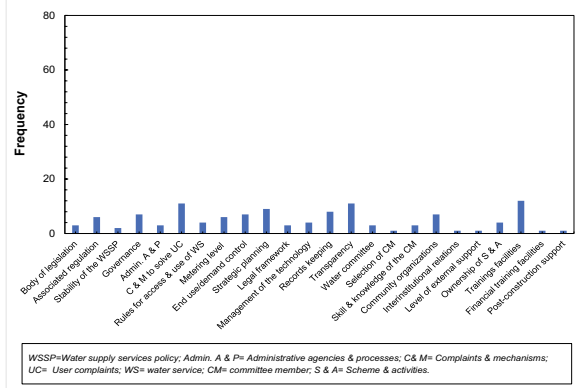

f) Policy, legislation, regulations, \& institutions

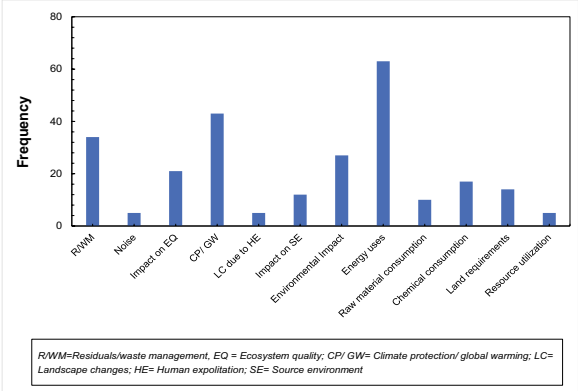

h) Environmental footprint

Fig. 3 Water security assessment indicators and the frequency of their occurrence in the literature for a) watershed and source water; b) community characteristics \& engagement; c) technical performance (treatment \& distribution); d) technical performance (operation \& maintenance); e)socio-cultural aspects; f) policy, legislation, regulations \& institutions; g) budget, costs, \& equity; and, h) environmental footprint 


\section{A Drinking Water Security Assessment Framework}

A comprehensive set of drinking water security system assessment indicators and possible data variables appropriate for small communities in high-income country contexts have been synthesised from the literature and augmented through expert opinion and research experience (Table 1). The indicators are grouped into four themes, namely watershed security, source water security, community engagement, and water treatment and distribution system according to the conceptual framework (Fig. 1). Each theme is further subdivided into categories and sub-categories with associated indicators (Fig. S1).

Watershed Security Upstream ecosystem services can be assessed in terms of the extent and changing extent of forests [SI25] and wetlands and associated management strategies (Ontario Ministry of Natural Resources and Forestry 2017). Natural disturbances, such as floods, wildfires, and other extreme events, pose significant threats to water quality (Khan et al. 2015) and therefore their risk of occurrence and magnitude must be assessed. Other threats to water quality, such as pesticide use to reduce the impacts of invasive species must also be assessed (CIPM 2020). Upstream threats to water quantity can be assessed in terms of water abstraction and construction or existence of dams in the upstream. Construction of dams into the upstream can affect the hydrologic cycle as well as the flow pattern of the watershed (Pokhrel et al. 2018). Potential abstractions can be assessed for the industry use and exports or the volume of water that is already committed under licences or permits. The absence of landslides has also been used to assess the sustainability of rural water supply [SI33] as landslides can significantly increase sediment and pollution loads and block water courses under extreme circumstances (Geertsema et al. 2009). Industrial activity, agriculture, and impermeable landscapes (natural or anthropogenic) will also impact water quality and quantity depending on their areal extent. These are assessed under source water security as this is where more proximal impacts will occur. Adoption of watershed or aquifer protection and restoration strategies and use of green infrastructure can maintain and improve the quality and health of the ecosystem. Although these management strategies facilitate high quality and reliable water sources [SI110,24], they have rarely been accounted for in the context of drinking water security to date. Indigenous water stewardship strategies and Traditional Knowledge (McGregor 2012) must also be accounted for.

Source Water Security Source water security is typically assessed using indicators of water quantity, quality, and reliability, as well as potential threats and the existence of protection plans and incentives [SI10,52,55,63,127] which vary depending on the type of source (i.e., groundwater, surface water). Though the presence of a plan is the most common indicator, availability of technical, institutional, financial, and social capacity as well as proper legislation and regulation built on local knowledge and experience are important considerations for implementation and effectiveness [SI10] (Hirokawa 2012; Minnes and Vodden 2017). The availability of sufficient water for abstraction can be assessed by measuring the storage and change in storage of the water sources. Reliability can be assessed through seasonal variation in water storage as well as long-term variability (i.e., interannual change).

The amount of treatment required to meet drinking water standards or objectives is determined by the quality of the source water (Kloosterman et al. 2021). Hence, source water quality (i.e., treatability) as well as the degree of potential threats, such as local 


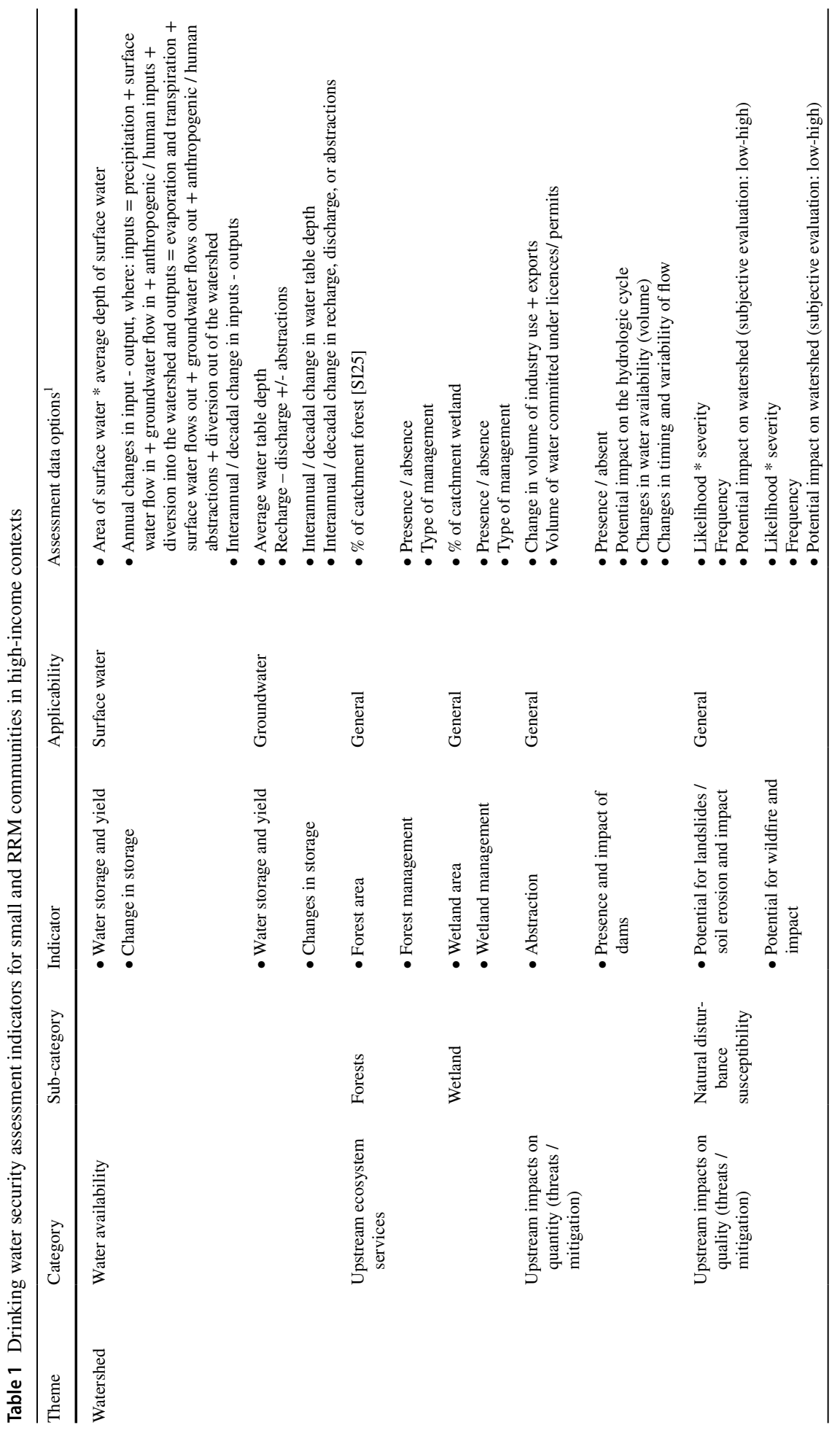




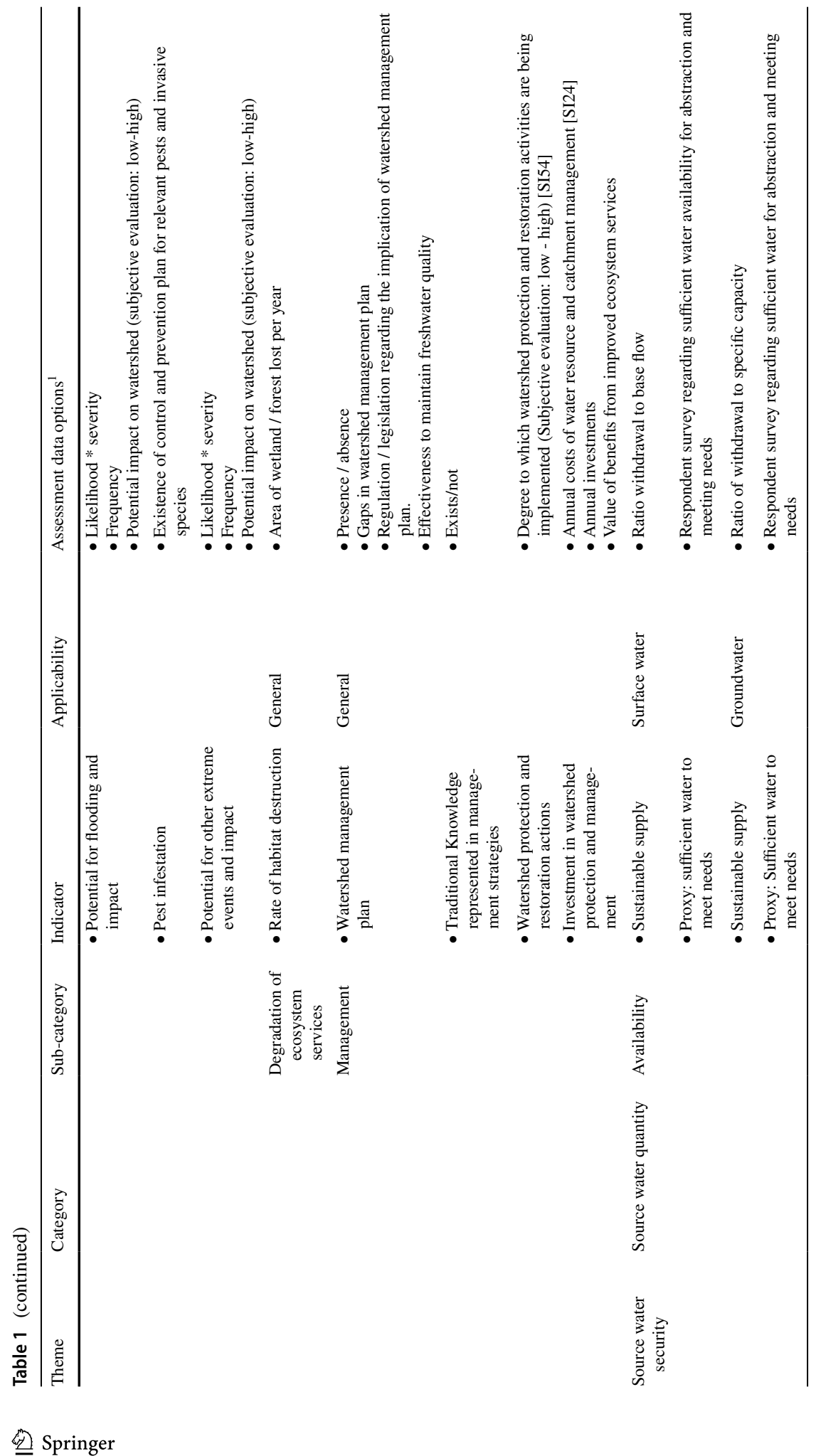




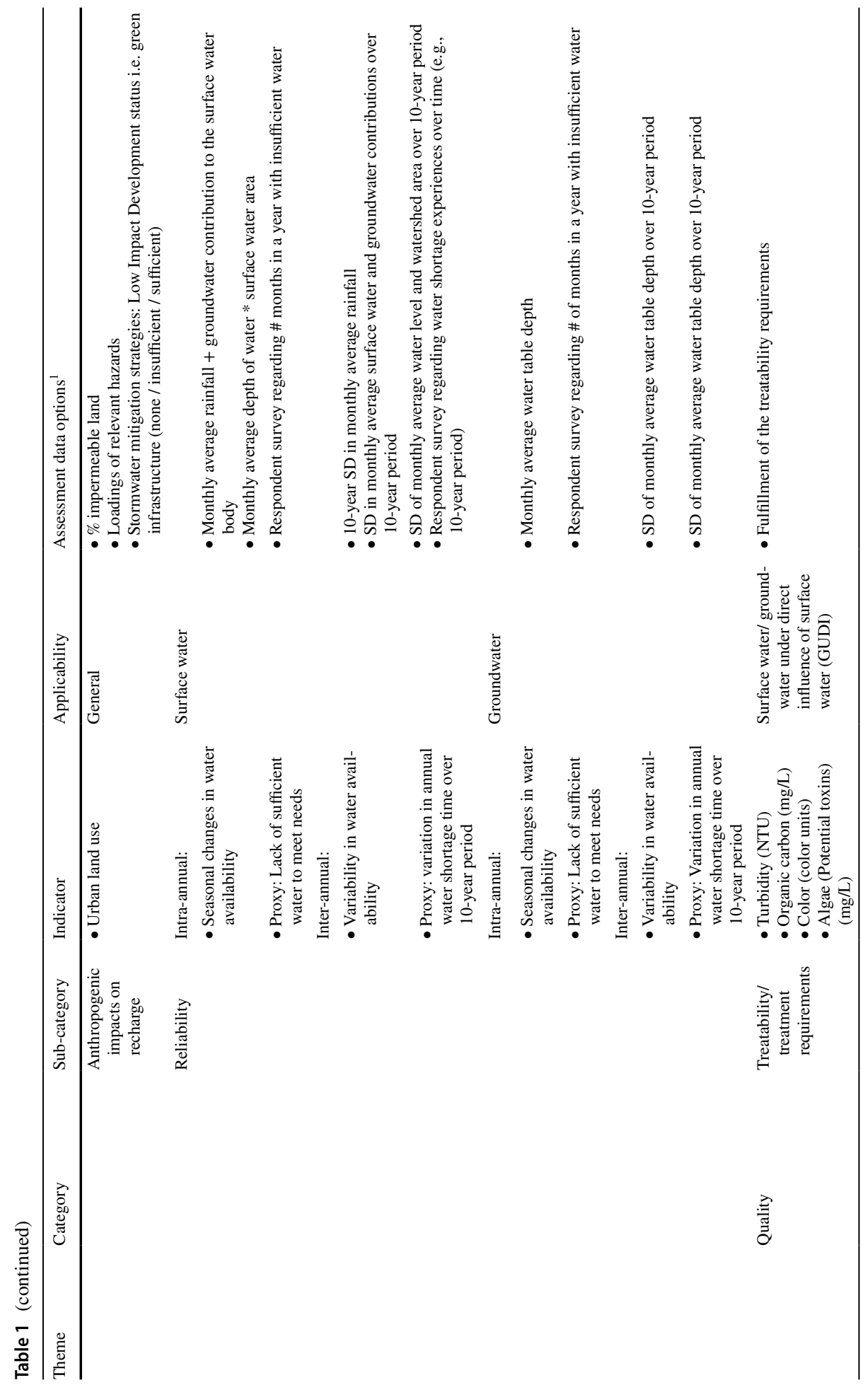




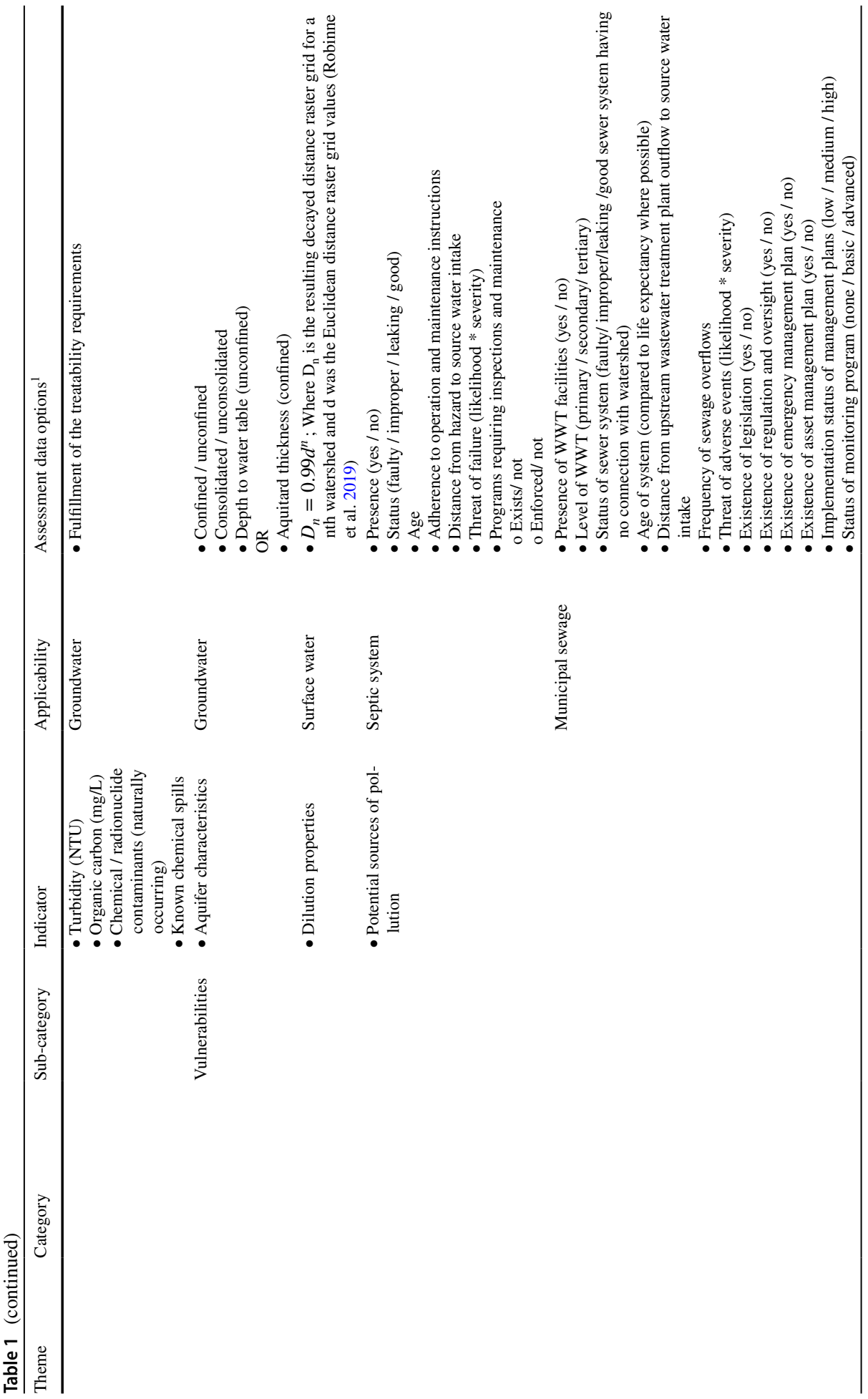




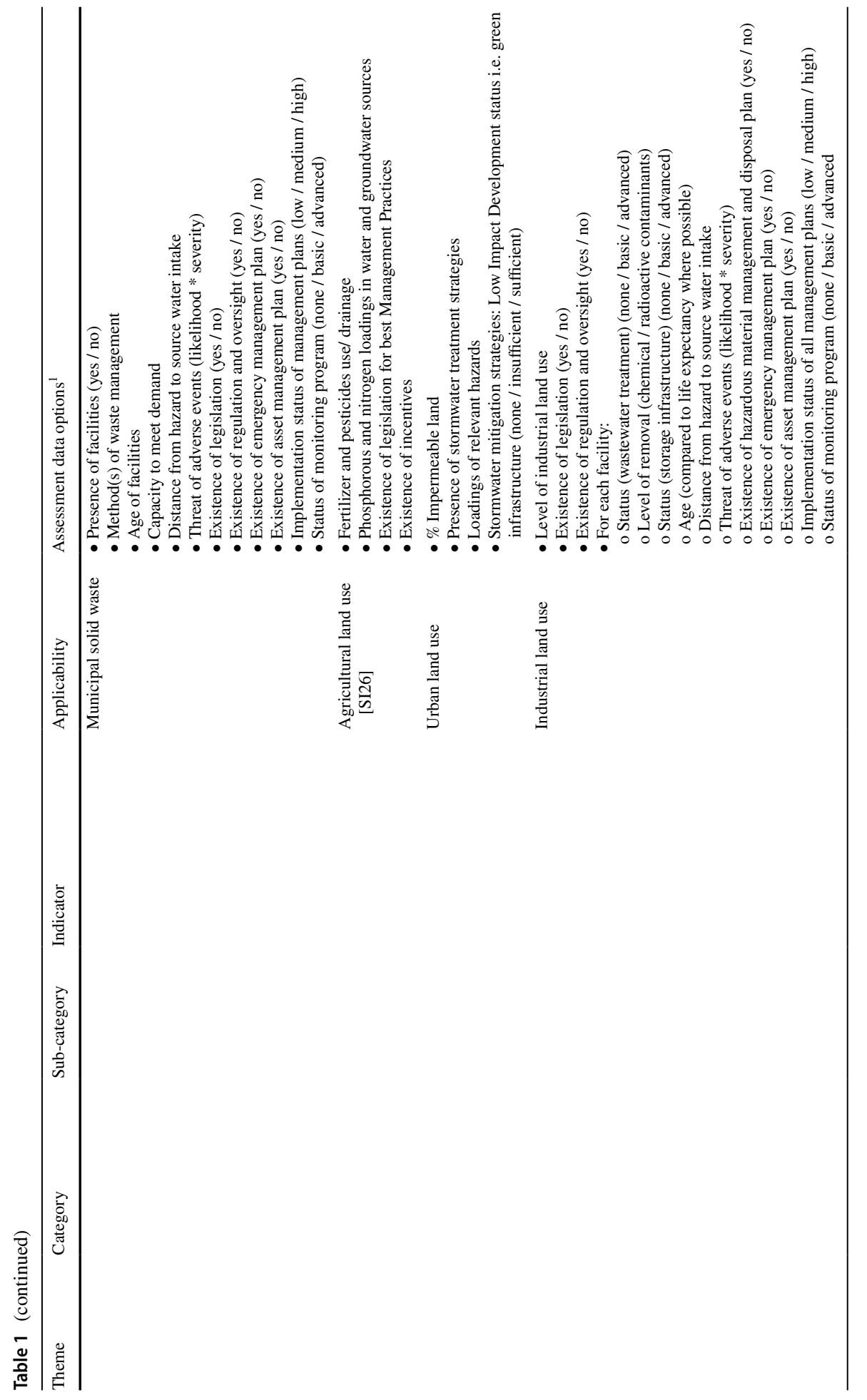




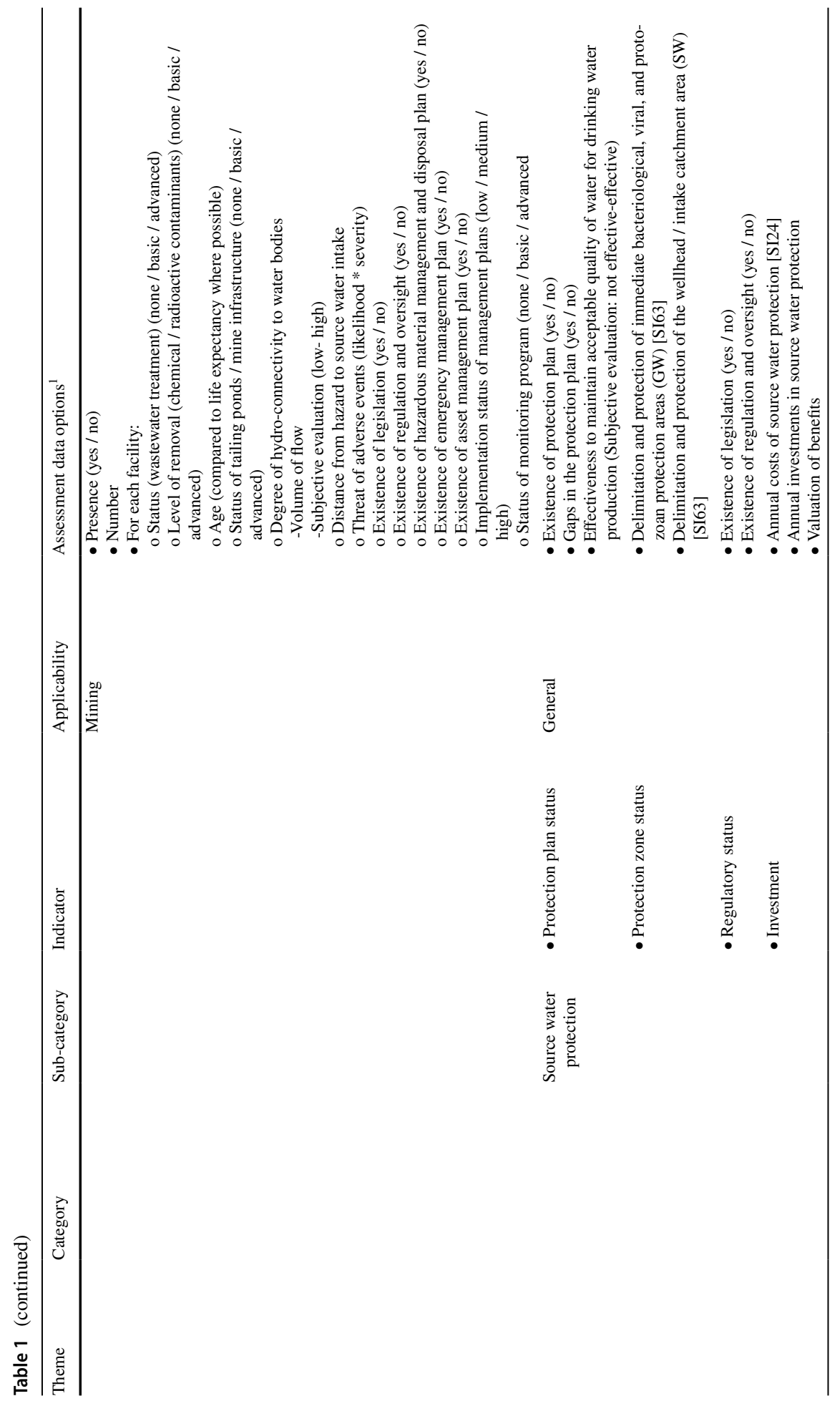




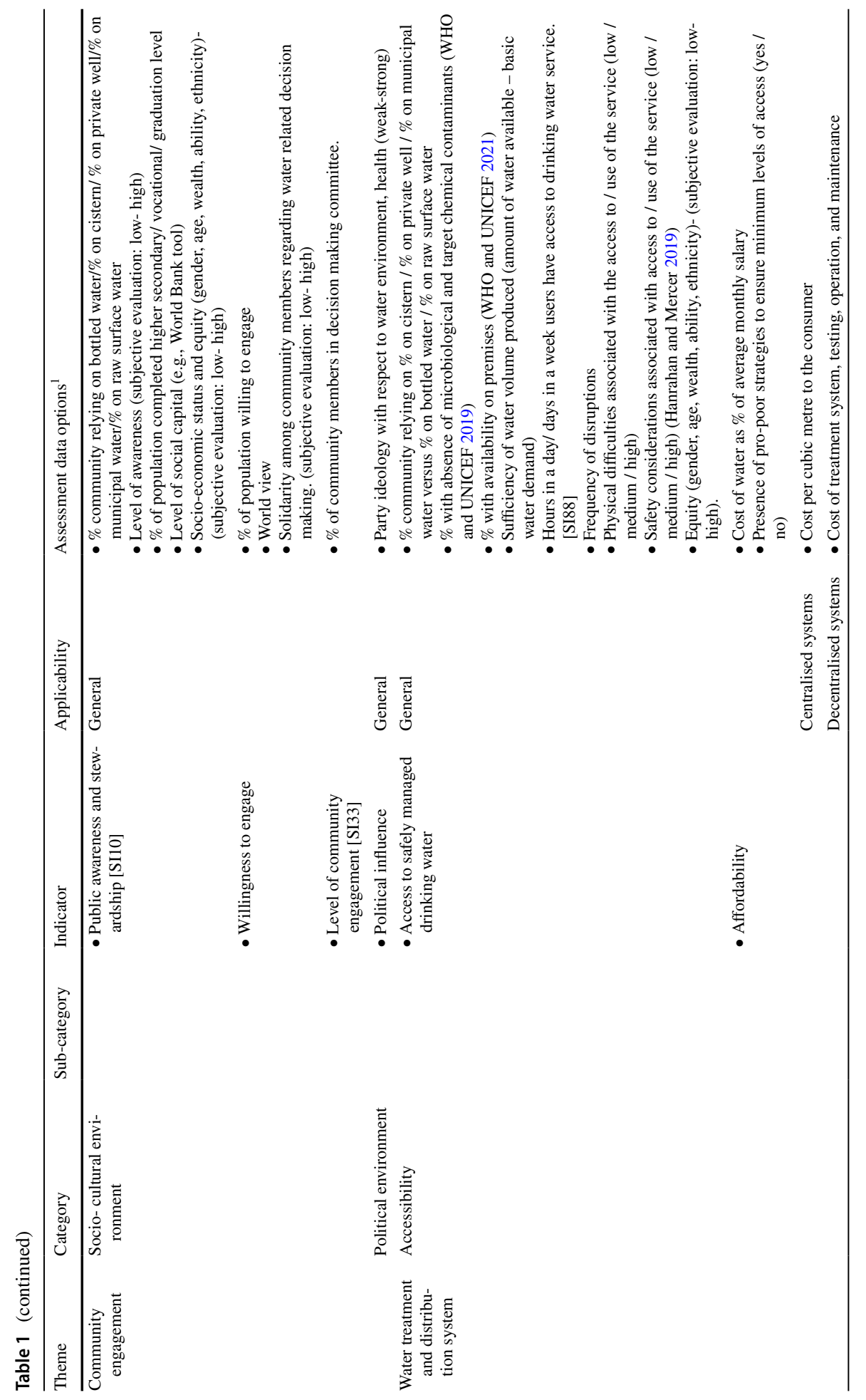




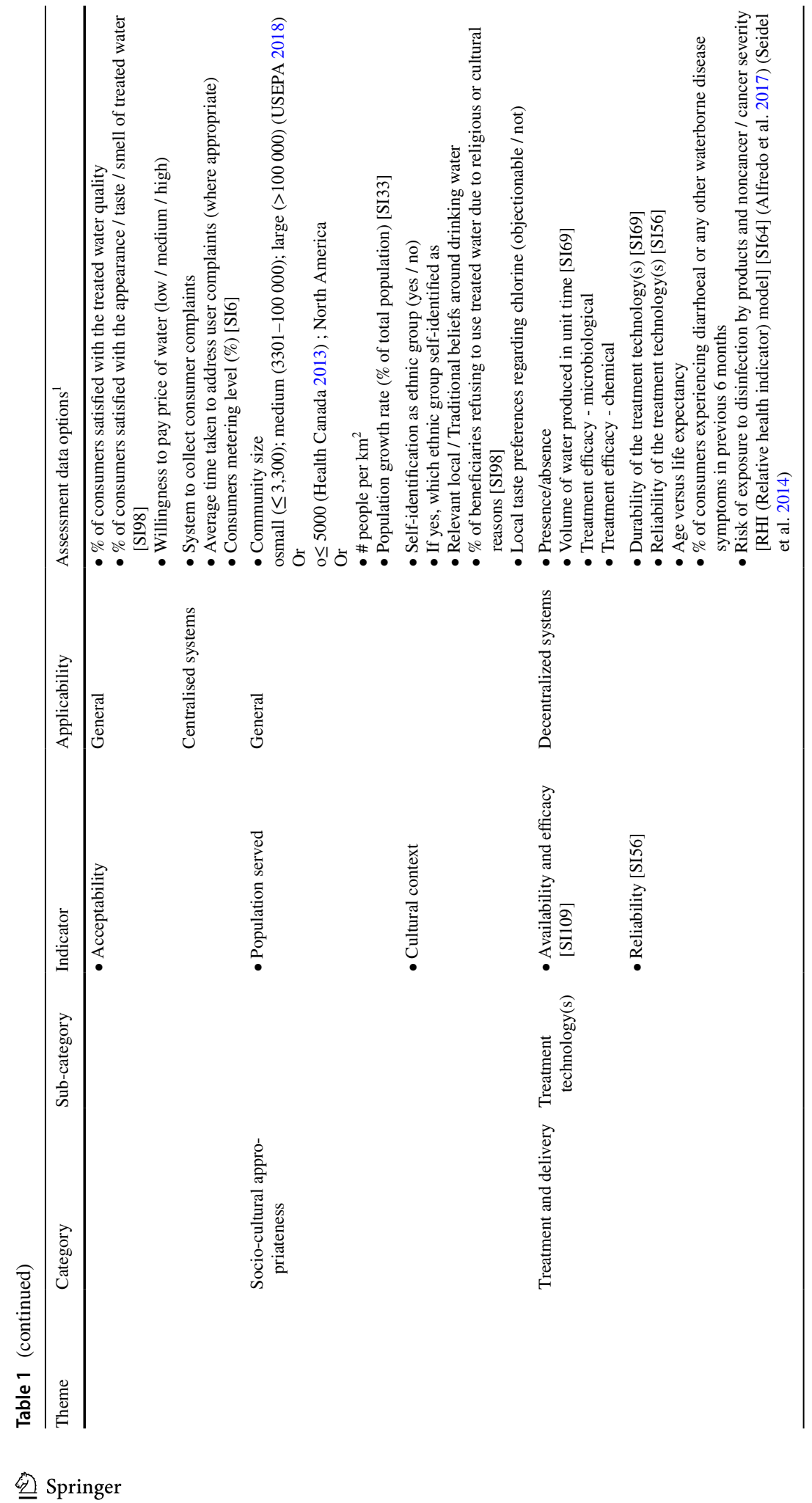




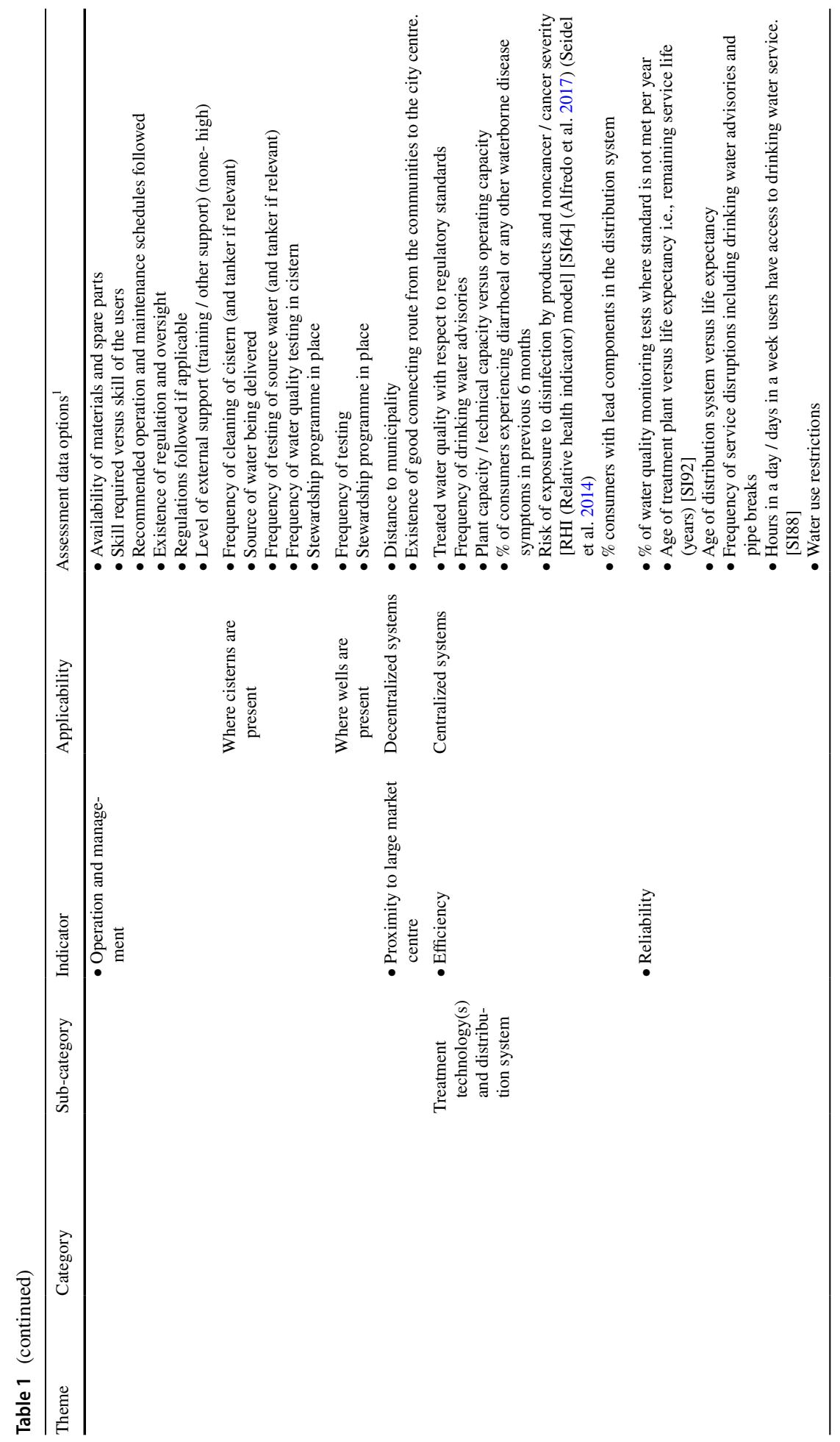




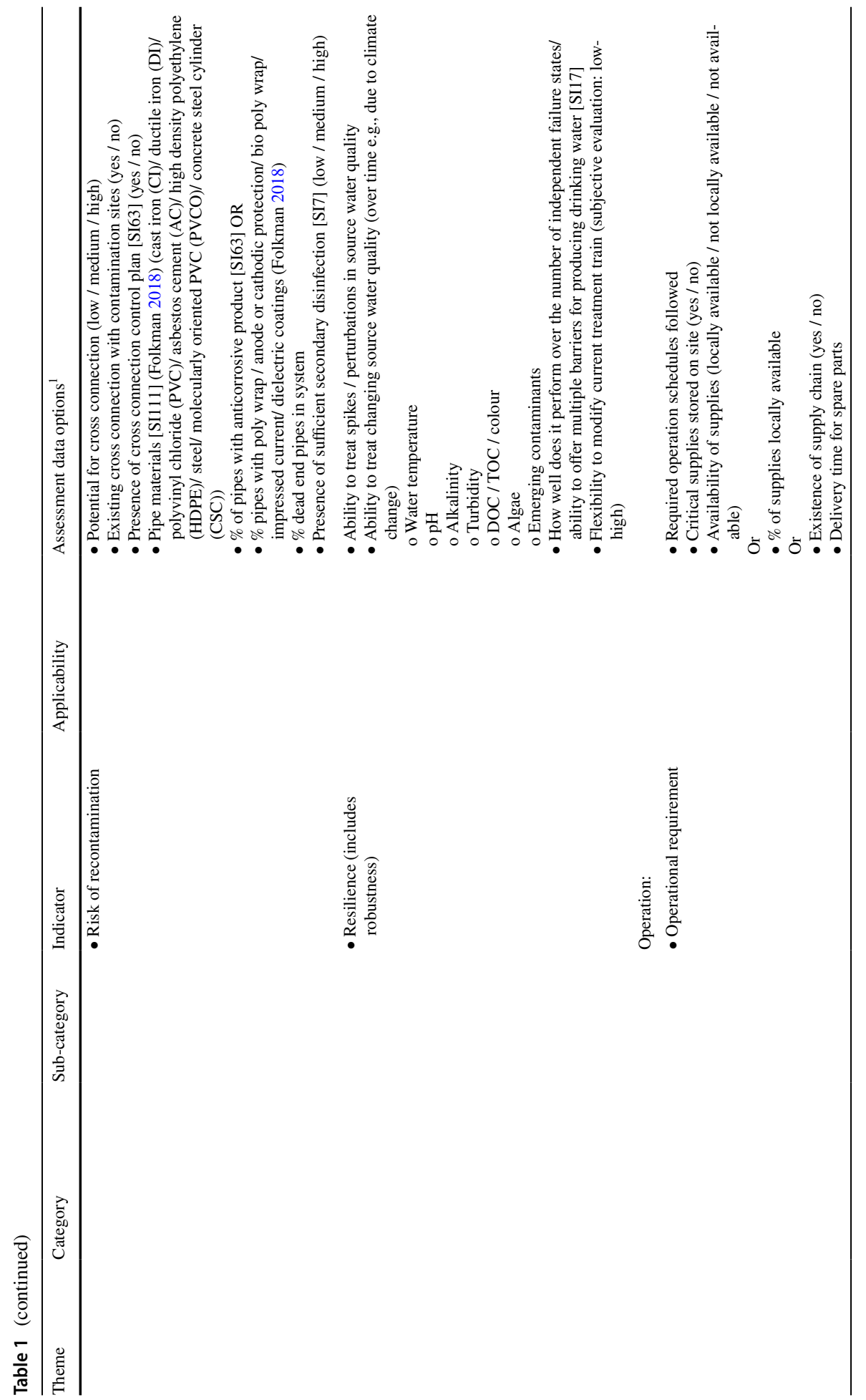




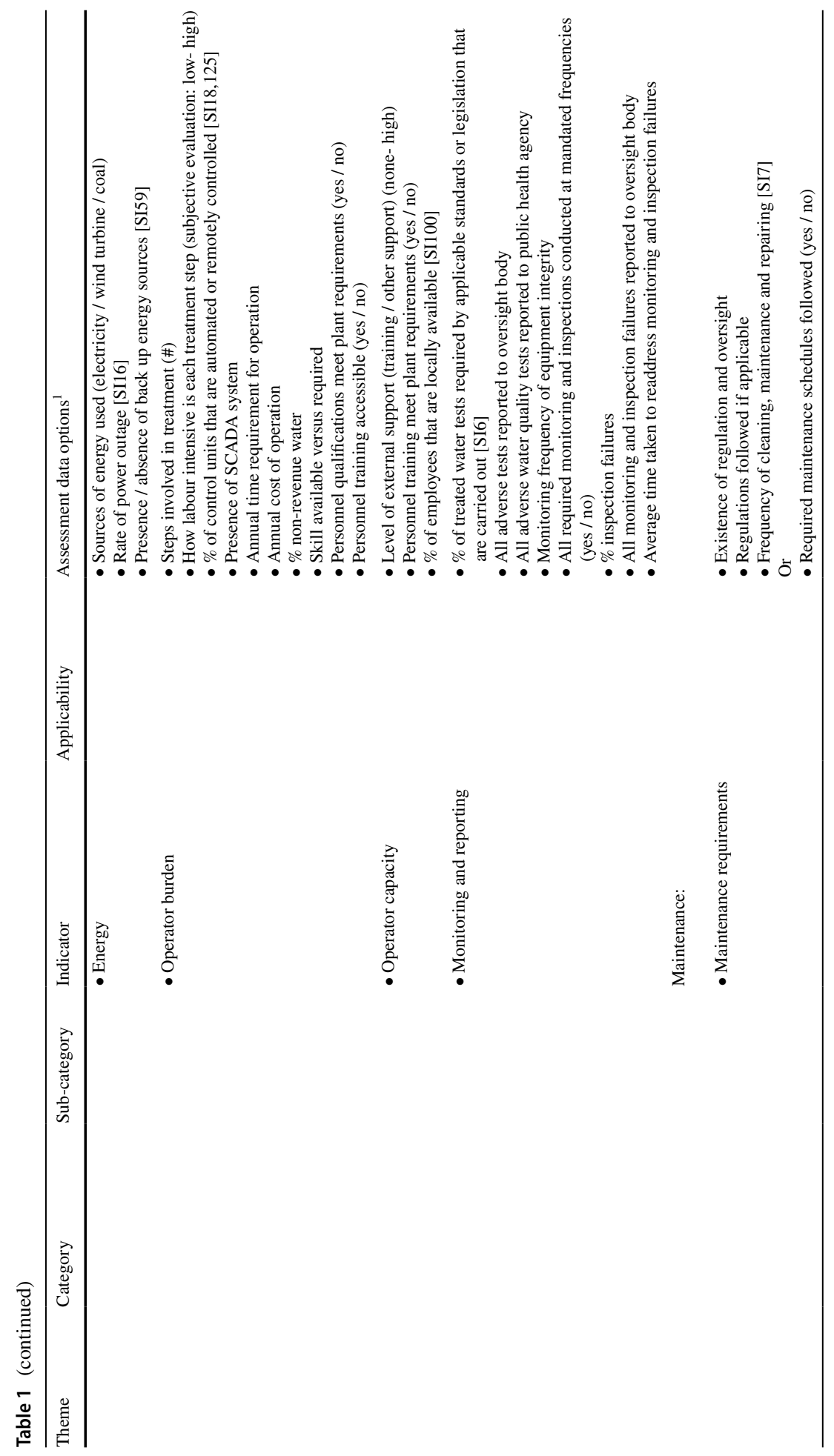




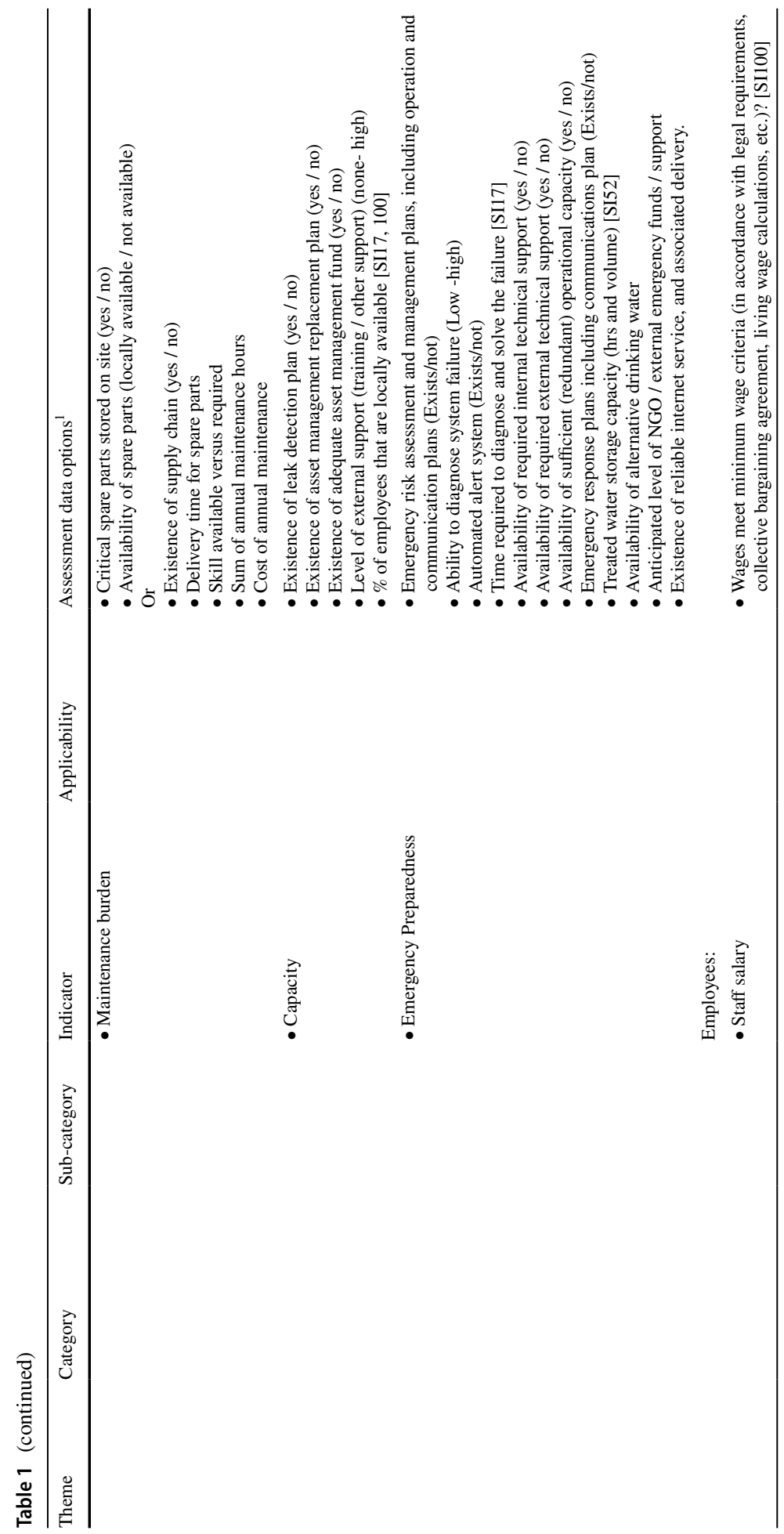




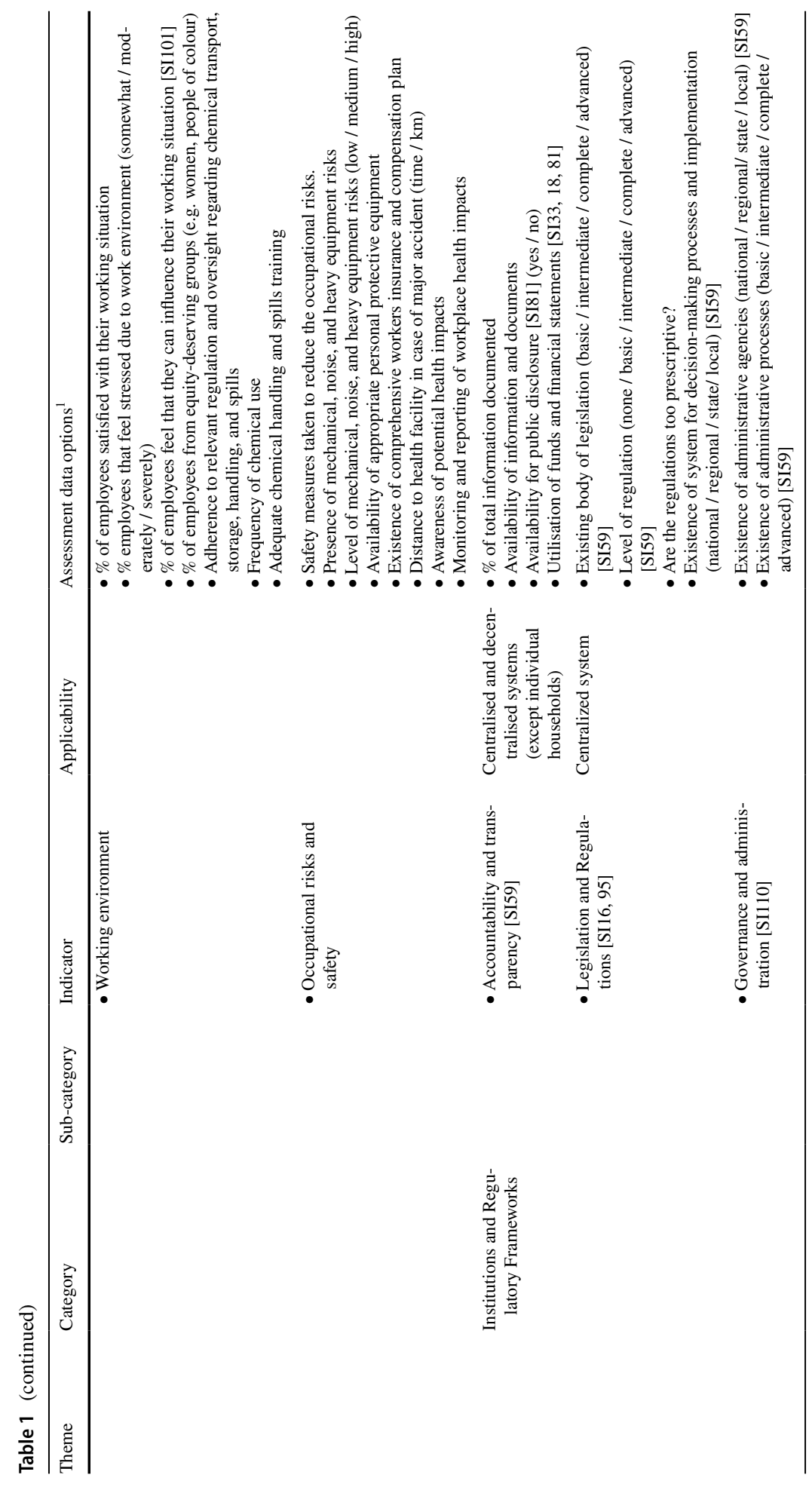




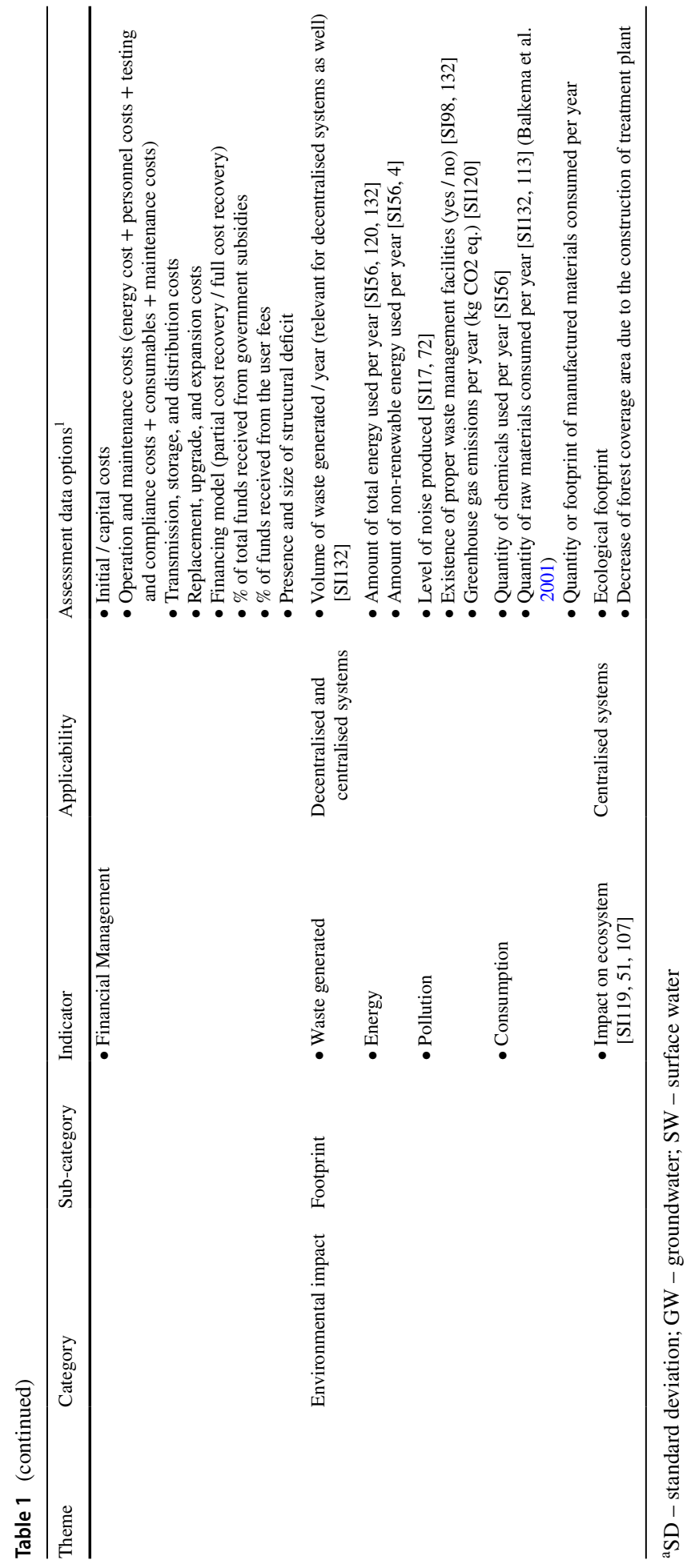


geology, industry, and agriculture [SI26,63] must be assessed. However, the existence and oversight of best management practices (BMPs) (e.g., stormwater management, low impact development infrastructure, and manure management), regulations, and legislation must also be considered as they can mitigate these threats.

Community Engagement The awareness, participation, and responsibility of water consumers has impacts on water stewardship and conservation, which makes them important indicators of local community engagement, and therefore drinking water security [SI10,33]. Level of education, social capital, and socio-economic status and equity among different groups including people with different gender, age, wealth, ability, ethnicity are important for sustaining and deepening engagement (OECD. 2015; Case and Zeglen 2018). Successful community involvement further depends on the existing cultural and political environments (White et al. 2012). Research with Indigenous communities in Canada demonstrates that differences in perceptions of water quality may be the result of different worldviews and understandings of water health (White et al. 2012; Yates et al. 2017). Political party ideology with respect to water, environment, and associated health is another essential indicator to evaluate the political influence on drinking water decision making (Bullock and Bowman 2018).

Water Treatment and Distribution System Performance indicators for the water treatment and distribution systems are categorized into accessibility; socio-cultural appropriateness; treatment and distribution infrastructure; existing policy, legislation, regulations, and institutions; and environmental footprint. Indicators are identified for both centralized and decentralized systems (Table 1). Despite the fact that a majority of the population in highincome countries have continuous access to potable water in their homes, access is not universal. For example, a study in Nunatsiavut, Labrador, identified that many residents only had restricted access to municipal water and relied on bottled water and natural surface water sources (Goldhar et al. 2013).

Some studies have used accessibility as a metric to assess the sociocultural sustainability of the treatment and distribution infrastructure [SI18, 134], which itself is assessed in terms of the distance, effort, ability, barriers and dangers, and time required to access the service [SI7] (Dickson et al. 2016; Hanrahan and Mercer 2019). Sustainability of the infrastructure can be assessed through quantity of produced water [SI34], safety considerations (Hanrahan and Mercer 2019), service disruptions [SI88], cost of water [SI107], equity [SI10], and socio-economic status [SI138]. Pro-poor strategies are important even in high-income countries to ensure that access is not interrupted due to lack of finances (Minnes and Vodden 2017; McFarlane and Harris 2018). Recently, many US states and cities placed a moratorium on water shutoffs during the COVID-19 pandemic (Warner et al. 2020). Social equity is also important as access can be insufficient for marginalized or oppressed groups (Schuster-Wallace and Dickson 2017) and can be demonstrated through many examples globally from Indigenous communities to inner city populations (e.g., Flint MI 2014).Acceptability is another important indicator affects whether people use the treated drinking water or choose alternative sources [SI120] (Minnes and Vodden 2017). Public perceptions and acceptability of water quality tend to rely on aesthetic propertiessuch as colour, smell, and taste-that may not be good indicators of the parameters that pose potential health risks (Kot et al. 2015). Existence of proper mechanisms to collect and solve user complaints are not used as metrics in the current literature for drinking water security problem analysis, despite the potential to enhance the acceptability of centralized 
systems. User engagement more broadly should be considered as part of the solution towards redressing Indigenous water inequities. Indigenous cultural beliefs and values may align better with certain treatment technologies, but when there is insufficient consultation disconnects occur (Schuster-Wallace and Dickson 2017; Latchmore et al. 2018). For example, chemical water treatment is believed to kill the spirit of water in some Indigenous cultures (Lawless et al. 2015) and adds an unnatural taste to water, particularly in sub-standard systems where residual chlorine levels may be high and cause adverse health effects (Minnes and Vodden 2017). These values need to be understood as they can reinforce collection and consumption from natural, untreated sources [SI7] (Daley et al. 2015; Latchmore et al. 2018). Finally, it is important to consider population size and growth rates as well as community development opportunities in order to project expected demands for water within technology service lifetimes. This is critical in small and RRM communities where treatment systems are often capacity-limited (McFarlane and Harris 2018).

Technical performance and sustainability of the treatment and distribution infrastructure depends on numerous factors including the efficacy, reliability, resilience, operation and maintenance, capacity, and personnel (Table 1). Drinking water provision is decentralised when supplied at the site of the demand, whether at the individual or small local level. Performance indices of decentralized treatment infrastructure include availability and efficacy, reliability, operation and maintenance burden, and proximity to large market centres (e.g., supply chains). Efficacy of the treatment infrastructure evaluates the ability to produce water of desirable quantity and quality whereas reliability measures the ability of the technology to perform steadily under stated conditions [SI45]. Occurrence of diarrhoea or waterborne diseases can be used to identify failures in efficacy. Reliability is affected by durability and service life, but many studies use one or the other [SI69]. In this framework, both are integrated into service reliability in addition to year-round efficacy. Treatment performance depends largely on operation and maintenance status, which in turn depend on affordability and availability of the required materials and spare parts, and stewardship, training, and awareness programmes. For advanced and sophisticated technology, absence of skilled users can reduce performance significantly. Proximity to larger market centres can be a source of skilled labour as well as materials and spare parts, a consideration that has yet to be included in the literature. Operation and maintenance schedules should be followed accordingly to reduce risk of recontamination and avoid off-line periods. For larger, centralized systems, performance indices for treatment and distribution infrastructure include efficiency, reliability, resilience, risk of recontamination, operation and maintenance, and personnel. The efficiency can be assessed by evaluating treated water against regulatory standards (quality) and plant capacity (quantity) [SI7] (Kokkinos et al. 2019). Disinfection by-product (DBP) occurrence is one of the common issues in small communities (Minnes and Vodden 2017). As such, risk of exposure to DBPs, assessed using a Relative Health Indicator (RHI) model [SI64] (Alfredo et al. 2017), can be another metric for efficiency. Drinking water advisories are frequently issued for small communities due to the lack of sufficient and reliable water supply, which can also be used. Given that the efficiency of the treatment and distribution systems depend largely on operating conditions, evaluation of both technical and operating capacity can be used to identify potential capacity improvement. Reliability can be assessed through water quality monitoring and exceedances of drinking water standards [SI7,20]. The sufficient and continuous supply of drinking water in centralized systems depends on various factors including water use restriction, water access restriction, service disruptions, and age (even though this is sometimes included as a separate indicator [SI92]). Risks of recontamination in the distribution system include cross connections, pipe materials [SI111], and secondary disinfection [SI7]. 
Resilience, defined as the ability to maintain performance in the face of short- and longterm variability in water quality and quantity [SI138], such as sea level rise (e.g. SI57), has been assessed through resilience in the treatment train [SI64], robustness, flexibility, and adaptive capacity (e.g. SI47), but can also utilise the presence of a multiple barrier approach to drinking water (O'Connor 2002). Performance of the treatment and distribution infrastructure in centralized systems depends largely on the operation and maintenance of the system. Monitoring facilitates early problem identification that enables timely action, mitigating threats to public health (e.g., Hrudey and Hrudey 2007). Monitoring and reporting further provide information about changes in the water source and assurance that the treatment system is working properly (Ministry of Health 2013). Operator capacity reflects the ability of the operational personnel to operate and maintain the system effectively. This includes the operational and maintenance requirements [SI7], availability of qualified staff [SI52], and access to necessary equipment (and supply chains) [SI17], training facilities, and external supports [SI33]. Previous studies have used indices such as required skills [SI69] and time effort [SI59]. In this framework operator burden is introduced to assess workload, time, and skill requirements against operator capacity. Use of automated [SI18] and supervisory control and data acquisition (SCADA) systems can reduce work load and chances of human error. Asset management can help to ensure appropriate human and financial resources are available for maintenance, rehabilitation, and replacement over the infrastructure life cycle [SI106]. The reliability of the energy supply system [SI132], rate of outage [SI16], and existence of back up systems [SI59] are also critical for system performance. Work environment for personnel is strongly aligned with operational performance, despite little attention in the literature [SI52]. Salary [SI100], and working conditions, including satisfaction and stress levels [SI101], as well as occupational health and safety measures, risks, and injuries [SI132, 17, 99], are important elements of the work environment to be evaluated. Emergency preparedness is another important indicator; the ability of water utility operators to respond rapidly in an emergency will help prevent unnecessary complications and protect the health and safety of consumers (Health Protection Branch 2016). Effective and transparent institutions, along with legislation, regulation, and oversight, governance and administration, and financial management are important for ensuring reliable operation and maintenance and protecting public health [SI42,59] (McFarlane and Harris 2018). Additionally, proper utilization and management of funds underpin long-term sustainability and confidence. Accountability and transparency further enhance trust between operators and managers and their communities, including proper documentation and accessible information which also improve consumer drinking water literacy and confidence. Thus, it is important to assess the accountability and transparency status for small systems.

Environmental footprint is a critical consideration, especially with many countries pledging carbon neutrality as part of climate action plans in response to the Paris Accord (United Nations Climate Change 2019). Drinking water treatment technologies can have negative impacts on the environment, particularly local landscapes and ecosystems. These are caused by concentrated effluents, treatment by-products, solid waste, emissions (including greenhouse gasses), noise, energy demand, materials and chemical consumption, and overall carbon [SI56,52,83,5]. Energy requirements are particularly important to consider and depend on several factors including the location of the demand with respect to the source, raw water quality, technology, and age of the infrastructure (Pichel et al. 2019). The total energy required informs operating costs [SI132, 120]. However, the proportion of non- renewable energy use [SI4] can be used to assess the environmental resource depletion and provide insight to renewable energy offsets and opportunities. Excessive 
resource consumption is associated with the depletion of resources. Some studies emphasize resource availability rather than consumption (e.g., SI59, 98) while others emphasize resource utilization (e.g., SI22). Consumption of resources should be assessed in terms of chemical use [SI132, 120], and raw [SI132] and manufactured material requirements. Lastly, impacts on the environment can be assessed in terms of the ecological footprint [SI5] and reduction of forest coverage resulting from construction, operation, and maintenance of the system. Life cycle impact assessment methods, such as IMPACT 2002+ (Jolliet et al. 2003), can be used to assess the ecological footprint [SI64].

\section{Implementation of the Framework}

In order to support decision-making processes, indicators need to be assessed to ensure that all indicators chosen are relevant and appropriate to the local context. Subsequent weighting and aggregating of the indicators are needed to support prioritization and decision making (Molinos-Senante et al. 2019; Octavianti and Staddon 2021). However, assigning weights is one of the most challenging steps in multiple-criteria decision analysis (MCDA).

Several weighting processes exist including statistical methods, literature-based, expert opinion, and user opinion. The framework put forward in this paper utilises a source to consumer approach to drinking water security that is not prevalent in the literature to date. As such, the number of references to a specific indicator (literature-based weighting) is not a useful weighting system. In expert-based weightings, members are usually selected from internal decision makers or water providers (Bouchard et al. 2010) and can include technical, operational, administrative, social, and economic expertise (Schuster-Wallace et al. 2018; Molinos-Senante et al. 2019), but this fails from a community engagement perspective.

Despite the relative ease of connecting with end users, very few studies allocate weights based on user opinions. For this reason, even the weighting process can exclude peoples' needs and voices. However citizen science surveys and stakeholder feedback systems can be facilitated through social media and the internet, for example using the internet of things (IoT) platform to express preferences for qualitative and quantitative criteria (Pallavi et al. 2021). Given a call for prioritisation of, for example, socio-cultural appropriateness and environmental impacts and resources over economic costs (Fig. 2), the proposed framework includes indicators that require either quantitative or qualitative assessment as well as variables with different units of measurement. This presents challenges in terms of weighting schemes and must be considered. Several solutions are available in the literature for weighting and aggregating variables in decision-making processes, such as normalization (Octavianti and Staddon 2021), fuzzy clustering analysis, multilevel fuzzy methods, and system dynamics (e.g., Zarghami et al. 2018; Goyal et al. 2020), a coupled TOPSIS/ Entropy multi-attribute decision-making framework (Zolghadr-Asli et al. 2021), and analytic hierarchy process to combine scientific and expert information (Pagano et al. 2021).

Individual communities can develop their own weighting schemes, but if an inter-community comparison is required, both the variable inclusion and weighting scheme must be developed at the regional/multi-community level. Once weightings have been established, benchmarks must be set towards the goal of achieving drinking water security within the local context. This is an iterative process that should be used to inform watershed and source water planning and management, treatment technology investments, and 'greening' 
operational efficiencies. However, it should be noted that this approach also requires watershed-based planning units that often conflict with political boundaries.

\section{Conclusion}

A framework for drinking water security in small and RRM communities has been presented along with indicators and metrics. Not only does this framework recognize the importance of the broad upstream context, but also emphasises the importance of community engagement in visioning and goal setting to ensure that values and needs are recognised. Integration of the essential elements of the framework (upstream watershed security; source water security; community needs and engagement; and treatment and distribution infrastructure) and a shift away from economics as the primary priority, collectively contribute to long-term sustainability and enhanced local drinking water security.

Various agencies and organizations around the world have developed detailed performance evaluation frameworks and indicators that in most cases are limited to the treatment and distribution systems. Expanding the framework, and therefore increasing the breadth of literature scoped, along with expert opinion and research experience, culminated in a comprehensive and flexible list of indicators for assessing drinking water security from headwater to consumer. The resulting framework has multiple applications towards enhancing drinking water security, including risk awareness and mitigation, selecting appropriate technologies, prioritizing investments, and performance assessment. This is particularly important for small and RRM communities in high-income contexts given changing environmental conditions, small populations, human and financial resource challenges, and less autonomy in watershed management and planning.

Supplementary Information The online version contains supplementary material available at https://doi. org/10.1007/s11269-021-02985-2.

Authors Contributions This paper was conceptualized by C.J. Schuster-Wallace and S.E. Dickson-Anderson. B. Deb Nath surveyed the literature and extracted the indicators and indices. All authors finalized the indicators and indices. B. Deb Nath developed the first draft of the manuscript. All authors revised and finalized the manuscript. C.J. Schuster-Wallace and S.E. Dickson-Anderson provided supervision and funding for B. Deb Nath.

Funding This work was funded by the Natural Science and Engineering Research Council of Canada forWater NSERC Strategic Network (grant number NETGP-494312-16)

Availability of Data and Material The bibliography used to generate the assessment indicators and indices is provided as a table in the Supplementary Information.

\section{Declarations}

Conflicts of Interest/Competing Interests The authors declare no conflicts of interest.

\section{References}

Alegre H, Baptista JM, Cabrera Jr E et al (2016) Performance indicators for water supply services. IWA publishing 
Alfredo KA, Seidel C, Ghosh A, Roberson JA (2017) Using a relative health indicator (RHI) metric to estimate health risk reductions in drinking water. Environ Monit Assess 189:124

Balazs CL, Morello-Frosch R, Hubbard AE, Ray I (2012) Environmental justice implications of arsenic contamination in California's San Joaquin Valley: a cross-sectional, cluster-design examining exposure and compliance in community drinking water systems. Environ Heal 11:84

Balkema AJ, Preisig HA, Otterpohl R, Lambert AJ, Weijers SR (2001) Developing a model based decision support tool for the identification of sustainable treatment options for domestic wastewater. Water Sci Technol 43(7):265-269. https://doi.org/10.2166/wst.2001.0434

Black K, McBean E (2017) First Nations' water sustainability and Security Strategy: Tools and methodologies for community-driven processes for water treatment in Indigenous communities. Technol Soc 50:57-65

Blumenfeld S, Lu C, Christophersen T, Coates D (2009) Water, wetlands and forests. a review of ecological, economic and policy linkages. In: Secretariat of the Convention on Biological Diversity and Secretariat of the Ramsar Convention on Wetlands, Montreal and Gland. CBD Technical Series. p 38

Bouchard C, Abi-Zeid I, Beauchamp N et al (2010) Multicriteria decision analysis for the selection of a small drinking water treatment system. J Water Supply Res Technol 59:230-242

Bullock JB, Bowman AO (2018) Exploring citizens' support for policy tools at the food, energy, water nexus. Environ Prog Sustain Energy 37:148-154

Case RA, Zeglen L (2018) Exploring the ebbs and flows of community engagement: the pyramid of engagement and water activism in two Canadian communities. J Community Pract 26:184-203

CIPM (2020) Pesticide Environmental Stewardship. https://pesticidestewardship.org/. Accessed 6 Jan 2021

Coulibaly HD, Rodriguez MJ (2004) Development of performance indicators for small Quebec drinking water utilities. J Environ Manag 73:243-255

Daley K, Castleden H, Jamieson R et al (2015) Water systems, sanitation, and public health risks in remote communities: Inuit resident perspectives from the Canadian Arctic. Soc Sci Med 135:124-132

Dickson SE, Schuster-Wallace CJ, Newton JJ (2016) Water security assessment indicators: the rural context. Water Resour Manag 30:1567-1604

Domínguez I, Oviedo-Ocaña ER, Hurtado K et al (2019) Assessing sustainability in rural water supply systems in developing countries using a novel tool based on multi-criteria analysis. Sustainability 11:5363

Dunn G, Norman E, Bakker K et al (2012) Water security guidance document. Part 1 Sect 1 Defin Assess Water Secur 62

Edwards JE, Henderson SB, Struck S, Kosatsky T (2012) Characteristics of small residential and commercial water systems that influence their likelihood of being on drinking water advisories in rural British Columbia, Canada: a cross-sectional study using administrative data. J Water Health 10:629-649

Edzwald J (2011) Water quality \& treatment: A handbook on drinking qater, 6th edition. AWWA

Evans DD (2019) Appropriate technology for development: A discussion and case histories. Routledge

Farmer A, Dworak T, Bogaert S, Berglund M, Zamparutti T, Interwies E, Cools J (2012) Assessment of policy options for the Blueprint. Service contract to support the impact assessment of the Blueprint to Safeguard Europe's Waters

Folkman S (2018) Water main break rates in the USA and Canada: A comprehensive study

Forlee B, Mrwebi M, van Belle J-P, Chigona W (2014) Community engagement in drinking water supply management: A review

Gartner T, Di Francesco K, Ozment S et al (2017) Protecting drinking water at the source: lessons from US watershed investment programs. J Am Water Work Assoc 109

Geertsema M, Highland L, Vaugeouis L (2009) Environmental impact of landslides. In: Landslides-disaster risk reduction. Springer, pp 589-607

Goldhar C, Bell T, Wolf J (2013) Rethinking existing approaches to water security in remote communities: an analysis of two drinking water systems in Nunatsiavut, Labrador, Canada. Water Altern 6:462

Government of Canada (2021) Short-term drinking water advisories. https://www.sac-isc.gc.ca/eng/ 1562856509704/1562856530304. Accessed 4 Jan 2021

Goyal P, Kumar D, Kumar V (2020) Application of multicriteria decision analysis (MCDA) in the area of sustainability: a literature review. Int J Anal Hierarchy Process 12(3):512-545

Gunnarsdottir MJ, Gardarsson SM, Bartram J (2015) Developing a national framework for safe drinking water-Case study from Iceland. Int J Hyg Environ Health 218:196-202

Haider H, Sadiq R, Tesfamariam S (2014) Performance indicators for small-and medium-sized water supply systems: a review. Environ Rev 22:1-40

Hanrahan M, Mercer N (2019) Gender and water insecurity in a subarctic Indigenous community. Can Geogr Géographe Can 63:211-224

Health Canada (2013) Guidance for providing safe drinking water in areas of federal jurisdiction - version 2. https:// www.canada.ca/en/health-canada/services/publications/healthy-living/guidance-providing-safe-drinking- 
water-areas-federal-jurisdiction-version-2/page-5-guidance-providing-safe-drinking-water-areas-federaljurisdiction-version-2.html. Accessed 20 Oct 2020

Health Protection Branch (2016) Emergency response and contingency planning for small water systems. British Columbia, Canada

Hirokawa KH (2012) Driving local governments to watershed governance. Environ Law 157-200

Hrudey SE, Hrudey EJ (2007) Published case studies of waterborne disease outbreaks-evidence of a recurrent threat. Water Environ Res 79:233-245

Irvine A, Schuster-Wallace C, Dickson-Anderson S, Bharadwaj L (2020) Transferrable principles to revolutionize drinking water governance in first nation communities in Canada. Water 12:3091

Job C (2011) Characteristics of groundwater-supplied community water systems in the United States. Groundw Monit Remediat 31:36-38

Jolliet O, Margni M, Charles R et al (2003) IMPACT 2002+: a new life cycle impact assessment methodology. Int J life cycle Assess 8:324

Jones CH, Meyer J, Cornejo PK et al (2019) A new framework for small drinking water plant sustainability support and decision-making. Sci Total Environ 695:133899

Khan SJ, Deere D, Leusch FDL et al (2015) Extreme weather events: Should drinking water quality management systems adapt to changing risk profiles? Water Res 85:124-136

Kloosterman RA, van der Hoek JP, Herder P (2021) Resilient drinking water resources. Water Resour Manag 35:337-351

Kokkinos K, Lakioti E, Samaras P, Karayannis V (2019) Evaluation of public perception on key sustainability indicators for drinking water quality by fuzzy logic methodologies. Desalin Water Treat 170:378-393

Kot M, Gagnon GA, Castleden H (2015) Water compliance challenges: how do Canadian small water systems respond? Water Policy 17:349-369

Latchmore T, Schuster-Wallace CJ, Longboat DR et al (2018) Critical elements for local Indigenous water security in Canada: a narrative review. J Water Health 16:893-903

Lawless J-A, Taylor D, Marshall R et al (2015) Meaningful engagement: women, diverse identities and Indigenous water and wastewater responsibilities. Can Woman Stud 30(2-3):81-88

Lopes AF, Macdonald JL, Quinteiro P et al (2019) Surface vs. groundwater: The effect of forest cover on the costs of drinking water. Water Resour Econ 28:100123

Marshall A (Lia) (2015) When technology fails: insights on socially sustainable strategies in the water, sanitation, and hygiene sector. University of Washington

McFarlane K, Harris LM (2018) Small systems, big challenges: review of small drinking water system governance. Environ Rev 26:378-395

McGregor D (2012) Traditional knowledge: Considerations for protecting water in Ontario. Int Indig Policy J 3:11

Milly PCD, Betancourt J, Falkenmark M et al (2008) Stationarity is dead: Whither water management? Earth 4:20

Ministry of Health (2013) Small water system guidebook. British Columbia

Minnes S, Vodden K (2017) The capacity gap: Understanding impediments to sustainable drinking water systems in rural Newfoundland and Labrador. Can Water Resour J Revue Can Des Resour Hydriques 42:163-178

Molinos-Senante M, Muñoz S, Chamorro A (2019) Assessing the quality of service for drinking water supplies in rural settings: A synthetic index approach. J Environ Manage 247:613-623

Moreira NA, Bondelind M (2017) Safe drinking water and waterborne outbreaks. J Water Health 15:83-96

O'Connor DR (2002) Part two report of the Walkerton inquiry: A strategy for safe drinking water. Ministry of the Attorney General, Ontario, Canada

Octavianti T, Staddon C (2021) A review of 80 assessment tools measuring water security. Wiley Interdiscip Rev Water e1516

OECD (2015) Stakeholder engagement for inclusive water governance. IWA Publishing

Ontario Ministry of Natural Resources and Forestry (2017) A wetland conservation strategy for Ontario 2017-2030. Queen's Printer for Ontario. Toronto, ON

Pagano A, Giordano R, Vurro M (2021) A decision support system based on AHP for ranking strategies to manage emergencies on drinking water supply systems. Water Resour

Pallavi S, Yashas SR, Anilkumar KM et al (2021) Comprehensive understanding of urban water supply management: towards sustainable water-socio-economic-health-environment Nexus. Water Resour Manag 35:315-336

Pichel N, Vivar M, Fuentes M (2019) The problem of drinking water access: A review of disinfection technologies with an emphasis on solar treatment methods. Chemosphere 218:1014-1030 
Pokhrel Y, Burbano M, Roush J et al (2018) A review of the integrated effects of changing climate, land use, and dams on Mekong river hydrology. Water 10:266

Robinne F-N, Bladon KD, Silins U et al (2019) A regional-scale index for assessing the exposure of drinking-water sources to wildfires. Forests 10:384

Rubin SJ (2013) Evaluating violations of drinking water regulations. J Am Water Work Assoc 105:E137-E147

Schuster-wallace CJ, Dickson SE (2017) Pathways to a Water Secure Community. In The human face of water security (pp. 197-216). Springer International Publishing

Schuster-Wallace CJ, Murray SJ, McBean EA (2018) Integrating Social Dimensions into Flood Cost Forecasting. Water Resour Manag 32:3175-3187

Seidel C, Ghosh A, Tang G et al (2014) Identifying Meaningful Opportunities for Drinking Water Health Risk Reduction in the United States [Project\# 4310]. Water Res Found

United Nations Climate Change (2019) Climate action and support trends. Retrieved from https://unfccc.int/ sites/default/files/resource/Climate_Action_Support_Trends_2019.pdf

United States Environmental Protection Agency (2012) Drinking water: standards and risk management

USEPA (2018) Drinking Water infrastructure needs survey and assessment 6th report to congress, Office of Water, Washington, D.C. EPA 816-K-17-002

Van Engelenburg J, Van Slobbe E, Hellegers P (2019) Towards sustainable drinking water abstraction: an integrated sustainability assessment framework to support local adaptation planning. J Integr Environ Sci 16:89-122

Vieira P, Alegre H, Rosa MJ, Lucas H (2008) Drinking water treatment plant assessment through performance indicators. Water Sci Technol Water Supply 8:245-253

Warner ME, Zhang X, Rivas MG (2020) Which states and cities protect residents from water shutoffs in the COVID-19 pandemic? Util policy 67:101118

White JP, Murphy L, Spence N (2012) Water and indigenous peoples: Canada's paradox. Int Indig Policy J 3. https://doi.org/10.18584/iipj.2012.3.3.3

WHO and UNICEF (2021) Progress on household drinking water, sanitation and hygiene 2000-2020: Five years into the SDGs. World Health Organization and UNICEF, Geneva

WHO and UNICEF (2019) Progress on household drinking water, sanitation and hygiene 2000-2017: special focus on inequalities. World Health Organization

WWAP (United Nations World Water Assessment Programme) (2015) The United Nations world water development report 2015: water for a sustainable world. Paris

Yates JS, Harris LM, Wilson NJ (2017) Multiple ontologies of water: Politics, conflict and implications for governance. Environ Plan D Soc Sp 35:797-815

Zarghami SA, Gunawan I, Schultmann F (2018) System dynamics modelling process in water sector: A review of research literature. Syst Res Behav Sci 35:776-790

Zolghadr-Asli B, Bozorg-Haddad O, Enayati M, Goharian E (2021) Developing a robust multi-attribute decision-making framework to evaluate performance of water system design and planning under climate change. Water Resour Manag 35:279-298

Publisher's Note Springer Nature remains neutral with regard to jurisdictional claims in published maps and institutional affiliations.

\section{Authors and Affiliations}

\section{B. Deb Nath ${ }^{1}$ (D) C. J. Schuster-Wallace ${ }^{2}$ (D) . S. E. Dickson-Anderson ${ }^{3}$}

1 Department of Civil Engineering, McMaster University, Hamilton, Ontario, Canada

2 Department of Geography and Planning, University of Saskatchewan, Saskatoon, Saskatchewan, Canada

3 Department of Civil Engineering, McMaster University, Hamilton, Ontario, Canada 